\title{
Evaluation of Photogrammetric Documentation Options for Ancient Monuments
}

\author{
Funda Gençer ${ }^{1, *}$ and Mine Hamamcioğlu Turan ${ }^{2}$ \\ 1*Manisa Celal Bayar University, Faculty of Fine Arts, Design and Architecture, Department of \\ Architecture, Manisa, Turkey \\ ${ }^{2}$ Izmir Institute of Technology, Faculty of Architecture, Department of Architectural Restoration, \\ İzmir, Turkey
}

\begin{abstract}
This study has focused on 3D modelling of ancient monuments with multi-image photogrammetric documentation techniques. The aim of the study is to search the limits of multi-image photogrammetric documentation techniques that have automatic or manual workflows for deciphering of visual characteristic of ancient monuments with different geometries, positions, and site conditions.

Three parameters affecting the strategy and quality of the photogrammetric documentation are considered. The first parameter is the type of the photogrammetric software. The software which has manual workflows, Tgi3D SU, and two fully automated photogrammetric software, Photosynth and Autodesk 123D, are used in the study. Variation in the form, disposition and site of the monuments has been defined as the second parameter. In turn, four ancient monuments, which have all preserved their authenticity and presenting structural damages, but with various characteristic features, are studied; Hypokremnos Viaduct, Urla, İzmir; Pagos Cistern, Kadifekale, İzmir; Paradiso Aqueduct; Şirinyer, İzmir, and Nysa Library, Sultanhisar, Aydın; all in Western Anatolia. The third parameter affecting the strategy of the survey is the type of the 3D model aimed for; in other words, the documentation reason. 1/50 and 1/100 scale are selected for automatic documentation techniques, while 1/20 scale is selected for manual documentation technique.
\end{abstract}

3D model based on manual photogrammetric techniques is much more satisfactory compared to those based on automatic photogrammetric techniques in terms of accuracy control, level of geometric detail and documentation of surfaces. However, producing detailed models with manual techniques takes a relatively long time. The 3D models based on automatic workflows may support a preliminary condition survey. Autodesk 123D produces more successful results compared to works carried out with Photosynth-MeshLab combination.

Keywords: Documentation, ancient monument, photogrammetry, 3D modelling

\section{Introduction}

Documentation is the first step of the process of keeping built cultural heritage in a wellmaintained condition (UNI EN 16096, 2012). An ancient monument is generally an irregular formed and amorphous surfaced object as a result of its long-life span. Representation of ancient monuments should be a realistic 3D expression of the irregularity of the monument so that it can be taken as the basis for recommending preventive conservation or developing more detailed measures; possible reasons of documentation are detailed in European Standards, international conventions, charters, declarations and guidelines.

Traditional, tachometric, photogrammetric and laser scanning documentation techniques are used for gathering data with measured survey purposes of built cultural heritage (Böhler \& 
Heinz, 1999, Arias, et al., 2005, Remondino, 2011). In recent years, usage of photogrammetric techniques is preferred due to their fast, economic and easy to use properties in comparison to other techniques. According to specific needs in architectural documentation, different kinds of photogrammetric techniques were developed; digital image rectification, stereoscopic image measurement and multi-image measurement (Fellbaum 1992, Grussenmeyer, et al. 2002). In the last decade, software for multi-image measurement techniques creating realistic imagebased 3D models with textures from photographs by matching large group of photos manually or automatically have been developed. There are studies evaluating performance of multi-image photogrammetric documentation techniques taking into consideration software type, level of detail or object characteristics.

The type of photogrammetric evaluation software is the primary parameter that affects the quality of the architectural heritage survey. There are a number of studies (Böhler \& Heinz, 1999, El Hakim 2004, Remondino \& El Hakim, 2006, Guidi, et al., 2008, Barazzetti, et al., 2010, Annibale, 2011, Rosnell \& Honkavaara, 2012, etc.) comparing the point clouds restituted with quick, simple, low-cost, web based, and open source photogrammetric software such as Photosynth $^{\mathrm{TM}}$ and Bundler+CMVS2+PMVS2; and those restituted with conventional photogrammetric software. Automatic workflows require less restitution time, because it works without any orientation information, but the point cloud acquired with the manual workflow is more accurate (Barazzetti, et al., 2010).

The study of Annibale (2011) discusses how conventional and quick photogrammetric techniques can be used for optimizing the 3D modelling process of a complex architecture. The conventional Fangi (2007, 2008, 2009, 2010) software and the web-based software of Photosynth and Bundler+CMVS2+PMVS2 were the tools used. The point cloud restituted by the web-based software was a useful benchmark to start with the model reconstruction, but it lacked detail and scale. This preliminary model was used as a reference, and its details and scale were provided with the usage of point cloud acquired with conventional techniques.

In addition to the software preference, the characteristic features of the building are parameters taken into consideration, while deciding on the strategy of the survey. Guidi, et al., (2008) points out that buildings composed of elements with different geometric qualities should be surveyed with different strategies. For example, flat surfaces require a few points for modeling; but irregular and deficient building elements, and ornamentations require dense point clouds.

The third parameter affecting the strategy of the survey is the type of the 3D model aimed for; in other words, the documentation reason. Since scale is a means of filtering information, the determination of representation scale should be the first step in the documentation process so that the appropriate framework for classifying heritage information can be developed. If structural characteristics, deficiencies and failures are desired to be represented (Arias, et al., 2005), a conventional photogrammetric software e.g., Photomodeler Pro 4.0. should be preferred. In turn, the structured data such as the positioning, size and form of the walls and their openings can be taken as a reliable input in the identification of structural characteristics. In the study of Salonia et al. (2009), comparison of stereoscopic and trifocal documentation of archaeological and architectural artefacts at different scales were carried out, however object characteristics were not evaluated.

In this study, all mentioned parameters; type of software such as manual or automatic, the characteristics of the monument including its form, position and site; and the reason of documentation and the related presentation scale are evaluated together. Experiments were 
designed and tested on four ancient monuments. These are Hypokremnos Viaduct, Paradiso Aqueduct, Pagos Cistern and Nysa Library all in or at the vicinity of the metropolitan city of İzmir, Turkey. They have all preserved their authenticity, but present extensive structural failures and material deteriorations. Their geometric compositions, positions and site restrictions are different (Tab. 1).

All monuments were documented with software (Photosynth and Autodesk 123D) that have automatic workflows to gain models in 1/50 scale. However, in order to test the software that have manual workflows, (Tgi3D SU), Hypokremnos Viaduct, which has moderate dimensions in comparison to other monuments, was documented in 1/20 scale for the purpose of supporting structural intervention decisions (Tab. 1).

Two photogrammetric software both with automatic workflows (Microsoft $\AA$ 's Photosynth ${ }^{\mathrm{TM}}{ }^{1}$ and Autodesk 123D $\mathrm{Catch}^{2}$ ) and a software that has manual workflows (Tgi3D) was used. While Autodesk 123D Catch provides calibration, orientation and modeling automatically, Photosynth can just produce point clouds of objects automatically. Meshlab, a free mesh producing software, was used for surface construction of point clouds created with Photosynth. The Tgi3D includes manual evaluation, modeling, and texturing workflows in a single software package. After orientation was carried out in Tgi3D, surface reconstruction and texturing processes were also completed with Tgi3D plug-in for SketchUp 8 that contains 3D Image-Based Surface Modeler Tool. Modeling could be made in SketchUp 8 with the data exported from Tgi3D Calibration tool (Tab. 1).

\section{Characteristics of ancient monuments}

Hypokremnos Viaduct, Paradiso Aqueduct, Pagos Cistern and Nysa Library are located at the vicinity of the metropolitan city of İzmir. İzmir is a metropolitan city, with a coast of Aegean Sea, on the western side of Anatolia (Fig. 1).

Figure 1: Location of Izmir and ancient monuments

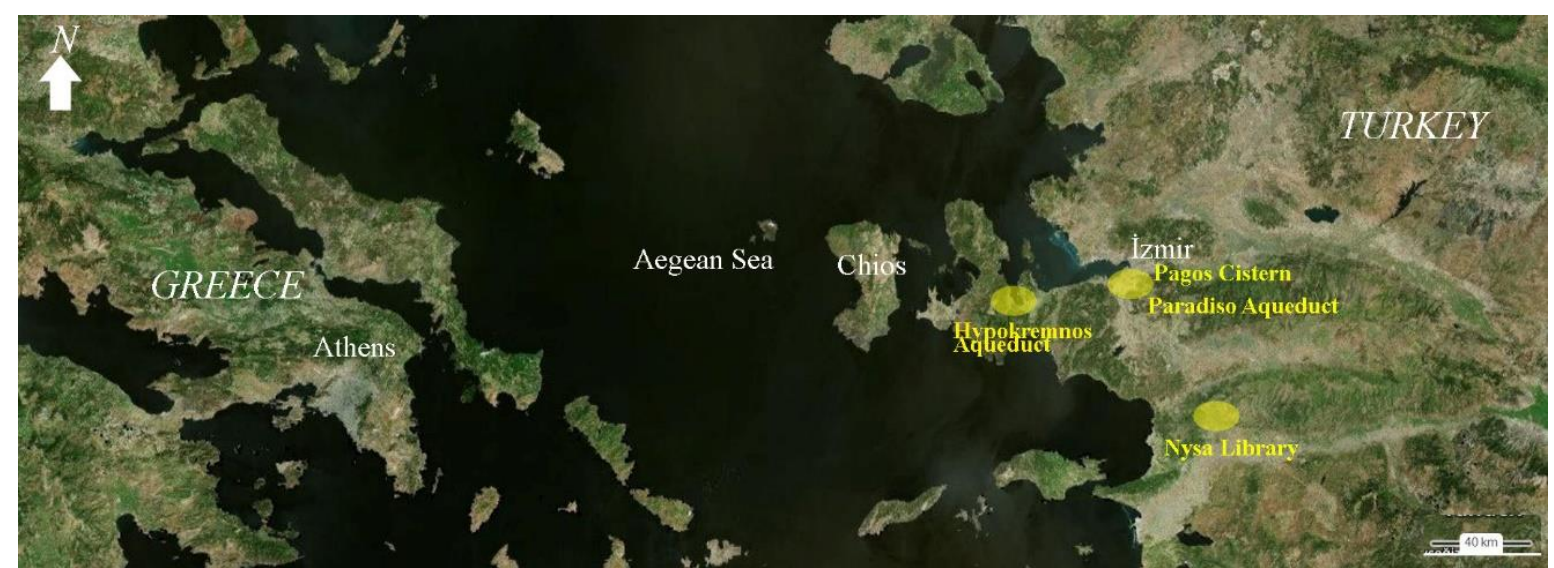

${ }^{1}$ Microsoft Photosynth, that was created on January, 2008, was used within the scope of this study at 2013. However, it has been dicommisioned on February 6, 2017. Microsoft brings back PhotoSynth in its Pix app for iOS on December 20, 2017. Only combination of photos is carried out and panoramas are created, point cloud of the object is not produced with this application.

\footnotetext{
${ }^{2}$ Autodesk 123D application, used within the scope of this study at 2013, integrates into commercial software, Recap Pro now.
} 
The first monument, Hypokremnos Viaduct (Fig. 2a), is part of a series of remains of viaducts crossing the brooks, on Hypokremnos Plateau, İçmeler, Urla, İzmir. An ancient road connecting Eryhtrai, Clazomenai and Teos cities was passing through Hypokremnos in Roman period (Bakır, et al. 1979). The viaduct is thought to be constructed first in Roman Period, and probably reconstructed with spolia after demolishment during Turkish period, which started in the 11th century in the region. It is a masonry structure with low and linear formed (W:3.49, L: 16.37, hmax:1.93 meters). Since it is located in the sea, sea wave is always splashing to the viaduct.

The second monument, Pagos Cistern (Fig. 2b), dated to Byzantine Period, is located on Mount Pagos in İzmir. Byzantine Emperor Ioannes III Vatatzes provided funds for its construction in the 13th century (Ersoy, 2012). The Cistern was constructed in the castle of Mount Pagos to provide water to the city as an underground chamber (Toksöz, 1960). Pagos Cistern has prismatic geometry, but it is depressed on ground. It was approximately 35.79 meters by 25 meters in dimension, but most of it is underground today. The portion observed today ( $21 \times 12$ meters) has lost its superstructure.

The third monument is Paradiso Aqueduct (Fig. 2c), crossing the valley of Meles Stream, in Şirinyer, at the south of the center of İzmir. It was a part of the water way supply channel constructed to convey water (Weber, 1889). It is a late Roman structure dating to 5th A.D. (Hodge Trevor, 2005, Weber, 1889). The linear and high water conduit (app. W:3, 1:120, hmax:1.2 meters), surrounded by shrubs and trees, is carried on bridgework composed of 17 arches positioned in rhythmic order at different levels.

The last monument, Nysa Library (Fig. 2d), is located in Nysa, an ancient city which is $3 \mathrm{~km}$ at the northwest of Sultanhisar and 30 kilometers at the east of Aydin province, at the southeast of İzmir. It is a Roman Library dated to ca. 130 A.D. taking into consideration its architectural ornaments (Hiesel \& Strocka, 2006). Nysa Library is composed of two prisms (app. W: 25, 1:20, hmax: 5.20 meters) on plain ground and surrounded by some shrubs.

Figure 2: a. Hypokremnos Viaduct, b. Pagos Cistern, c. Paradiso aqueduct, d. Nysa Library

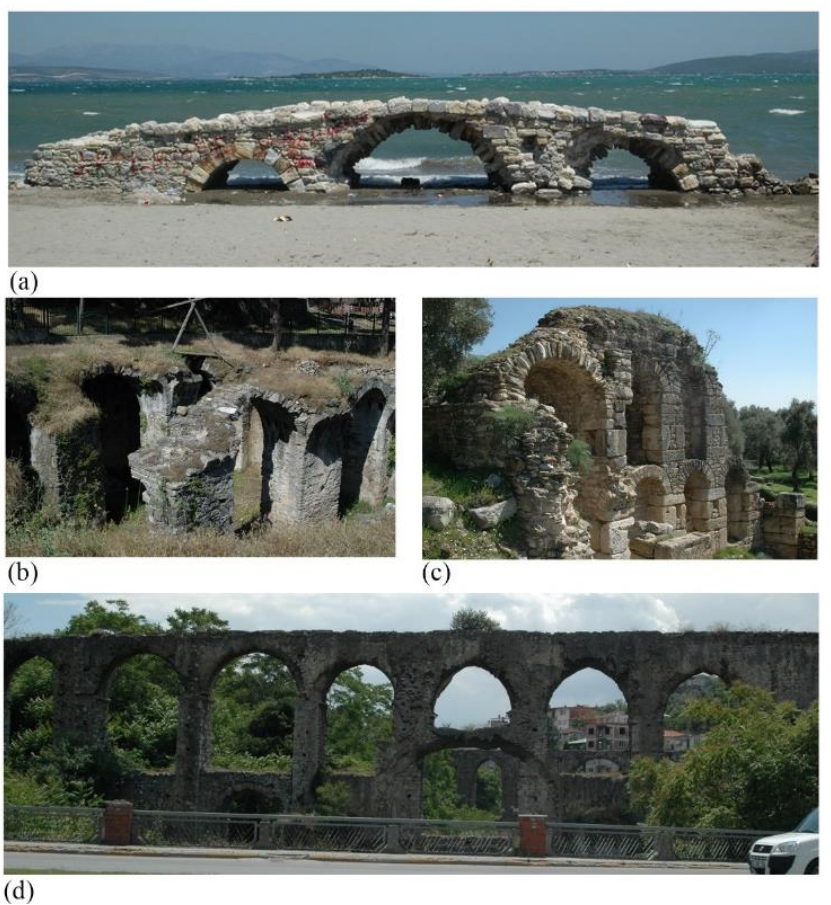




\section{Experimentation process}

Software types, scale and documentation necessities are identified to determine effect of parameters on efficinecy of documentation for each ancient monument considering their geometries, placements and site conditions (Tab. 1).

\begin{tabular}{|c|c|c|c|c|c|c|c|}
\hline & & \multicolumn{6}{|c|}{ PARAMETERS } \\
\hline & & Software & Geometry & Position & $\begin{array}{c}\text { Site } \\
\text { Restrictions }\end{array}$ & Scale & $\begin{array}{c}\text { Documentation } \\
\text { Necessity }\end{array}$ \\
\hline \multirow{9}{*}{ 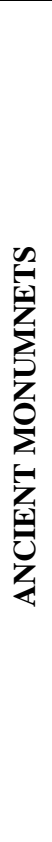 } & \multirow{3}{*}{$\begin{array}{c}\text { Hypokremnos } \\
\text { Viaduct }\end{array}$} & Photosynth+Meshlab & \multirow[t]{3}{*}{ Linear+Low } & \multirow{3}{*}{$\begin{array}{l}\text { Parallel to } \\
\text { coastline }\end{array}$} & \multirow{3}{*}{$\begin{array}{l}\text { Splashing sea } \\
\text { waves }\end{array}$} & $1 / 50$ & \multirow{2}{*}{$\begin{array}{l}\text { Condition } \\
\text { survey }\end{array}$} \\
\hline & & Autodesk 123D & & & & $1 / 50$ & \\
\hline & & Tgi3D & & & & $1 / 20$ & $\begin{array}{l}\text { Structural } \\
\text { investigation }\end{array}$ \\
\hline & \multirow[b]{2}{*}{ Pagos Cistern } & Photosynth+Meshlab & \multirow[t]{2}{*}{ Prismatic } & \multirow{2}{*}{$\begin{array}{l}\text { Depressed } \\
\text { on ground }\end{array}$} & \multirow{2}{*}{$\begin{array}{l}\text { Elevated } \\
\text { landscape in } \\
\text { its } \\
\text { surrounding }\end{array}$} & \multirow[t]{2}{*}{$1 / 50$} & \multirow{2}{*}{$\begin{array}{l}\text { Condition } \\
\text { survey }\end{array}$} \\
\hline & & Autodesk 123D & & & & & \\
\hline & \multirow{2}{*}{$\begin{array}{l}\text { Paradiso } \\
\text { Aqueduct }\end{array}$} & Photosynth+Meshlab & \multirow[t]{2}{*}{ Linear+High } & \multirow[t]{2}{*}{ On a brook } & \multirow{2}{*}{$\begin{array}{l}\text { Surrounded } \\
\text { by shrubs and } \\
\text { trees }\end{array}$} & \multirow[t]{2}{*}{$1 / 130$} & \multirow[t]{2}{*}{$\begin{array}{l}\text { Condition } \\
\text { survey }\end{array}$} \\
\hline & & Autodesk 123D & & & & & \\
\hline & \multirow{2}{*}{ Nysa Library } & Photosynth+Meshlab & \multirow[t]{2}{*}{ Prismatic } & \multirow[t]{2}{*}{$\begin{array}{l}\text { On plain } \\
\text { ground }\end{array}$} & \multirow{2}{*}{$\begin{array}{l}\text { Some shrubs } \\
\text { and debris in } \\
\text { its vicinity }\end{array}$} & \multirow[t]{2}{*}{$1 / 50$} & $\begin{array}{l}\text { Condition } \\
\text { survey }\end{array}$ \\
\hline & & Autodesk 123D & & & & & $\begin{array}{l}\text { Condition } \\
\text { survey }\end{array}$ \\
\hline
\end{tabular}

The experimentation process was composed of two steps, data gathering and data processing in both manual and automatic workflows.

\subsection{Data gathering}

Taking photographs was the first step for both software that have automatic and manual workflows. For data gathering, Nikon D70 digital SLR camera, equipped with 28-80 mm lense, a ladder and a steel tape (20 meters) were used. Targets were used just for manual photogrammetric technique. Three principals were considered; calculating shooting distance, designing image blocks and systemization of targets in the data gathering phase.

\subsubsection{Calculation of shooting distance}

Shooting distance was calculated according to Swallow's formula (Swallow, et al., 2004) (Eq. 1).

$$
\text { Negative Scale }=\text { Focal length } / \text { Distance }
$$

For automatic evaluation, to provide at 1/50 scale documentation, when focal length is accepted as $28 \mathrm{~mm}$, shooting distance was calculated as 5.5 meters. Since, Paradiso aqueduct has accessibility problems, it requires long shooting distance (app. 25 meters). So, related focal 
length was arranged according to this shooting distance. For 1/100 scale, focal length was calculated as $62.5 \mathrm{~mm}$.

For manual evaluation, to provide at $1 / 20$ scale documentation, when focal length was accepted $28 \mathrm{~mm}$, shooting distance was calculated as 2.25 meters.

\subsubsection{Designing image block}

Photos describing the object in general, and photos parallel to the surfaces of the object and all overlapping with each other were taken for both automatic and manual evaluation.

For Autodesk 123D, general and overlapping photos, around 50 and should not exceed 70, are taken by surrounding the ancient monuments. However, to gain a detailed point cloud in Photosynth, both detailed and general photos are necessary. Angle between the detailed photos is limited at least 15 per full rotation and maximum 25 degrees' angle (Fig. 3).

Figure 3: Data gathering principles for automatic evaluation processes
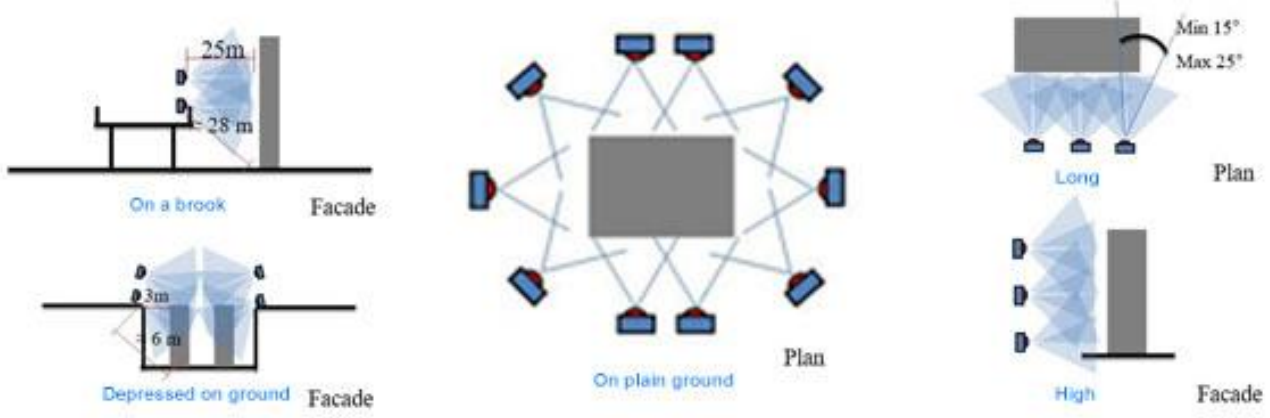

For manual evaluation, except general and overlapping photos, extra two photos for each parallel position, from its left and right sides and making approximately $45^{\circ}$ angle with the bisector of the viewing angle of the related parallel position were taken. In addition, three more extra photos for each parallel position were taken to support the manual evaluation process. These are shots made from the top of a ladder placed at the position of each parallel and its two sides, making the above describe angle (Fig. 4).

Figure 4: Data gathering principles for manual evaluation process

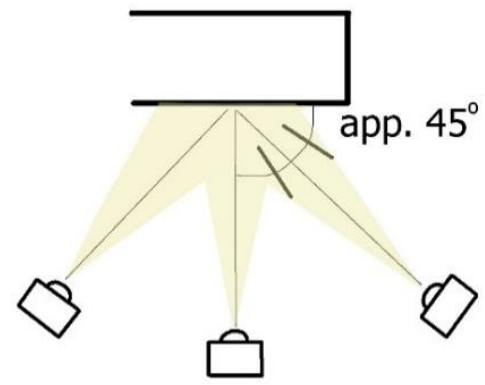




\subsubsection{Systemization of targets}

Targets were used just for manual work flow. Each photo included at least sixteen targets and four of the side targets were shot in the overlapping photo.

\subsection{Data processing}

Data processing phase is composed of two steps; point cloud generation and modeling.

\subsubsection{Point cloud generation}

Automatic software (Autodesk 123D and Photosynth) make it possible to combine large group of images. Images were uploaded to the software, and no more interaction was required. In Photosynth, point clouds are automatically placed at the disposal for the web community. According to quality of the output results, necessity of loading the images in groups was considered

- For Hypokremnos Viaduct, one image set containing 225 photos was uploaded to Photosynth.

- However, Pagos Cistern and Paradiso Aqueduct required loading images in groups due to the limitations in their positions and forms: two groups composed of 196 and 202 photos of each façade of the aqueduct; and four groups each composed of 210 photos of the cistern.

- For Nysa Library, 105 images were uploaded to Photosynth.

Autodesk 123D is fully automatic open source software containing both orientation and modeling tools. Also, it has manual orientation opportunity for photos that cannot be oriented automatically. The model produced can be viewed in wireframe and texture, and only texture formats. Its processing duration depend on the number of photos loaded.

- For Hypokremnos Viaduct, 71 images were uploaded. However, 9 of them were discarded. These nine photos were oriented with manual stitching method.

- 50 general images of Pagos Cistern taken from surroundings were uploaded to Autodesk $123 \mathrm{D}$.

- Front façade of Paradiso Aqueduct was evaluated with 99 images, since the software did not accept images of the rear façade due to the limitations in the shooting positions.

- 105 general images of Nysa Library taken from surroundings were uploaded to Autodesk 123D.

Tgi3d Su allow the orientation of images without any preliminary information about the sensors and do not require calibration. Orientation of image pairs was carried out manually. Minimum number of images with good photographic quality and best covering the object were selected. This selection was made intuitionally and if there were problems observed during the orientation, the photo set was revised.

Image sets were loaded to the software one by one, each image pair was oriented, respectively. Three control points were sufficient, while for long facades, four or five control points were used to strength bonding system for the corners and damaged short facades. With automatic addition of control points by the software, number of control points reached six for the long facades, and eight for the short facades. Max point error for each point was accepted as smaller than 3.23 pixels. A list of point errors is presented by the software, since point error of each oriented photo is calculated one by one. Two error values found according to this list 
were used in the calculation of the error of the model; maximum (max) error; the highest value and global error; the average value. When the maximum error value is high, orientation of the problematic photos has to be redone. First, 179 images were oriented, then thirty-one images were added to solve problematic parts on the floor of the viaduct.

At last, by using these point errors (max and global), the error in the reality-based model can be calculated. Error is calculated considering the shot length of the object at the site and in the image. It is calculated according to formula in the below.

$$
\begin{aligned}
& \mathrm{L}=\text { Shot length of the object at the site } \\
& \mathrm{N}=\text { Shot length of the object in the image } \\
& \text { Error } \sim \mathrm{L} / \mathrm{N} \text { x pixel error }
\end{aligned}
$$

\subsubsection{Reality-based Modeling}

In Autodesk 123D, which is fully automatic software, surface construction was carried out automatically. Photosynth does not provide reconstruction of surfaces. Surface construction of point clouds were carried out in Meshlab. Ball pivoting surface reconstruction filter was preferred for meshing process due to the irregular surfaces of the monuments. By using mesh cleaning and repairing filters, duplicated faces were removed, and holes were filled in.

After exporting the point cloud from Tgi3D to SketchUp 8, both the toolbars of SketchUp 8 and also the toolbar added to SketchUp 8 automatically by Tgi3D were used for modeling.

A 3d surface was drawn by connecting three control points on the images that are not tilted. This surface converted to real surface with Image-Based Surface Modeler toolbar. After the long southern façade of the viaduct wall was completed, its two short facades, the long northern facade, viaduct floor, and arches were modeled sequentially. During the surface construction, some problems as tilt seen in the images which were not taken with the camera lens parallel to the viaduct floor, inclusion of sky, water, and ground, drooping at the edges of the components, color differences due to the brightness differences between the images due to the different survey time and waves giving way to wet and dry surfaces were encountered. The solution developed for the tilt problem was returning to Tgi3D Calibration Tool and adding new photos which were not tilted instead of problematic ones. Inclusion and drooping problem were observed generally on the edges of the components. Therefore, parts including sky, water, and ground were edited with the help of the SketchUp tools. 


\section{Discussion}

Advantages and disadvantages of automatic and manual photogrammetric evaluations are discussed by taking into consideration success of 3D models of case studies.

\subsection{Advantages and Disadvantages of Automatic Photogrammetric Evaluation Software}

The major advantage of automatic techniques is the reduction they provide in data gathering and processing time. Sticking of targets on the surface of the structure is not necessary at the site. Taking photos parallel to the surface and illustrating object-surrounding relationship is the only process for the data gathering without the necessity of any further survey. In the office, calibration, orientation and surface construction phases were carried out by the software automatically. This increases the processing speed and prevents extra effort at the site and the office. The models produced with Photosynth and Autodesk 123D can be used for inventories, making preliminary evaluation and guiding limited emergency interventions. They can append a condition report of a built cultural heritage (UNI EN 16096, 2012). They illustrate a global reconstruction of the form of the ancient structures at $1 / 50$ or $1 / 100$ scales.

Despite these advantages, software that have automatic workflows have some drawbacks for the documentation of ancient structures. First, the automatic software does not provide an opportunity for viewing the accuracy of the measured point clouds; in turn the related realitybased models cannot be regarded as reliable sources for guiding the conservation applications.

The second drawback is the lack of detail in the reality-based model. Since the scales of the models cannot be reconstructed beyond the content of 1/50 scale, detail information including the amorphous surfaces of building material cannot be extracted from the models. In turn, structural intervention details cannot be planned based on the related documents.

The reality-based models which were gained by automatic techniques have incomplete surfaces and holes; so related presentations of models are not satisfactory. Filling these holes with surfaces is not preferred since these parts do not represent the original surface of the monument.

If two experimented automatic approaches are compared with each other, Autodesk 123D produces more detailed models compared to Photosynth. Among the ancient monuments, Nysa Library was the most advantageous one in terms of its compact mass, and surveyor-friendly site conditions. Models with Autodesk 123D may be useful for condition survey, while the point cloud produced with Photosynth for the Nysa Library is in sufficient for a meaningful 3D model.

When the software parameter is kept constant and reality-based models are compared with each other, the following results can be derived.

- The reality-based model of Hypokremnos Viaduct is moderately satisfactory since the roadway and the vaults cannot be shot parallel to their surfaces within general shots. Facades were modelled quite well in 1/50 scale since there were photos parallel to their surfaces could be easily shot. They may append the related condition report. But documentation of the vaults and the roadway are problematic (Fig. 5a).

- Reality based model of Pagos Cistern is unsatisfactory due to its depressed position. Photos are parallel to the object surfaces could not be shot. With objects in depressed positions, shooting process is relatively difficult. The photographs of lower parts of the object present limited number of points, because they can be covered in less number of photographs, taken 
from long distances and with more tilt (Fig 5b). The model may be useful for an overall understanding of the structure in 1/50 scale.

- Reality based model of Paradiso Aqueduct is unsatisfactory due to its elongated and high form, and shrubs, brook and trees restricting access (Fig. 5c). In turn, the restrictions just in front of the surface to be documented such as trees, shrubs, brook, etc. give way to long shooting distances (approximately $28 \mathrm{~m}$ ). The highness becomes a negative input because the photographs of the upper parts can be taken with more tilt. The model may be useful for an overall understanding of the structure in 1/130 scale.

- The reality-based model of Nysa Library is the most satisfactory due to its opportunities of geometry, position and site restrictions. Parallel shots of exterior surfaces and general views can be taken by walking around the monument (Fig. 5d). The 1/50 scale model may append the related condition report.

Figure 5: Models of monuments with Autodesk 123D, a. Hypokremnos Viaduct, b. Pagos Cistern, c. Paradiso Aqueduct, d. Nysa Library, eastern block

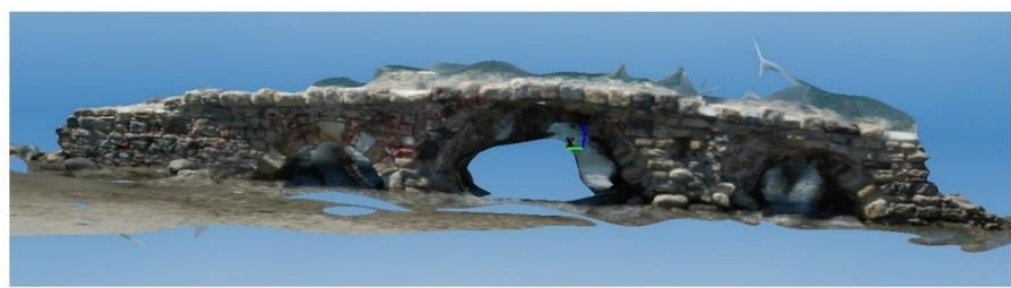

(a)

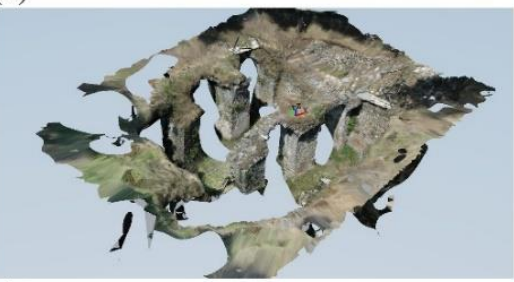

(b)

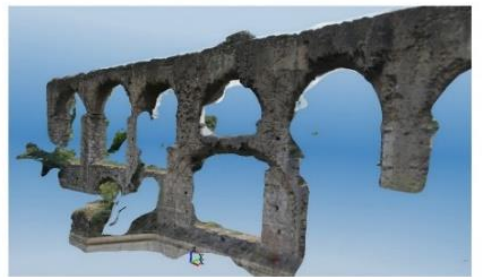

(c)

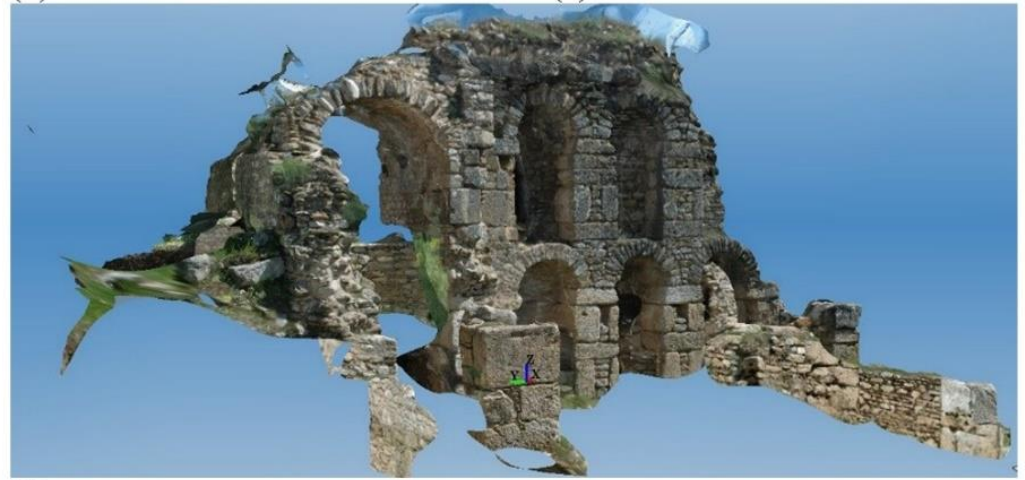

(d) 


\subsection{Advantages and Disadvantages of Manual Photogrammetric Evaluation Software}

The major advantage of the manual technique is the opportunity of viewing the point errors of the point clouds. Thus, reliable documents may be prepared for structural analysis. The precision of the 3D model produced with Tgi3 D is calculated considering maximum error value calculated by the software automatically, the shot length of the object at the site and in the image. The maximum error amount for $1 / 5$ scale is around $4 \mathrm{~mm}$, therefore, the end product model's precision is more than enough for the acceptable limits of $1 / 5$ scale.

Maximum error: 3.33 pixels.

Error $(\max ) \sim \mathrm{L} / \mathrm{N} \times$ pixel error $(\max )$.

Error $(\max ) \sim 3450 / 3000 \times 3.33$

$\sim 3.8 \mathrm{~mm}$.

The reality-based model does not have incomplete surfaces and holes in comparison to automatic evaluations, since these missing parts can be filled by creating meshes. This is the advantage of software directed by a human operator manually.

However, producing this detailed, satisfactory model takes a relatively long time. While working time at the site is short, data processing composed of orientation and modeling phases at the office is time consuming in comparison to automatic ones (Tab. 2)

Table 2: Duration of orientation and modelling

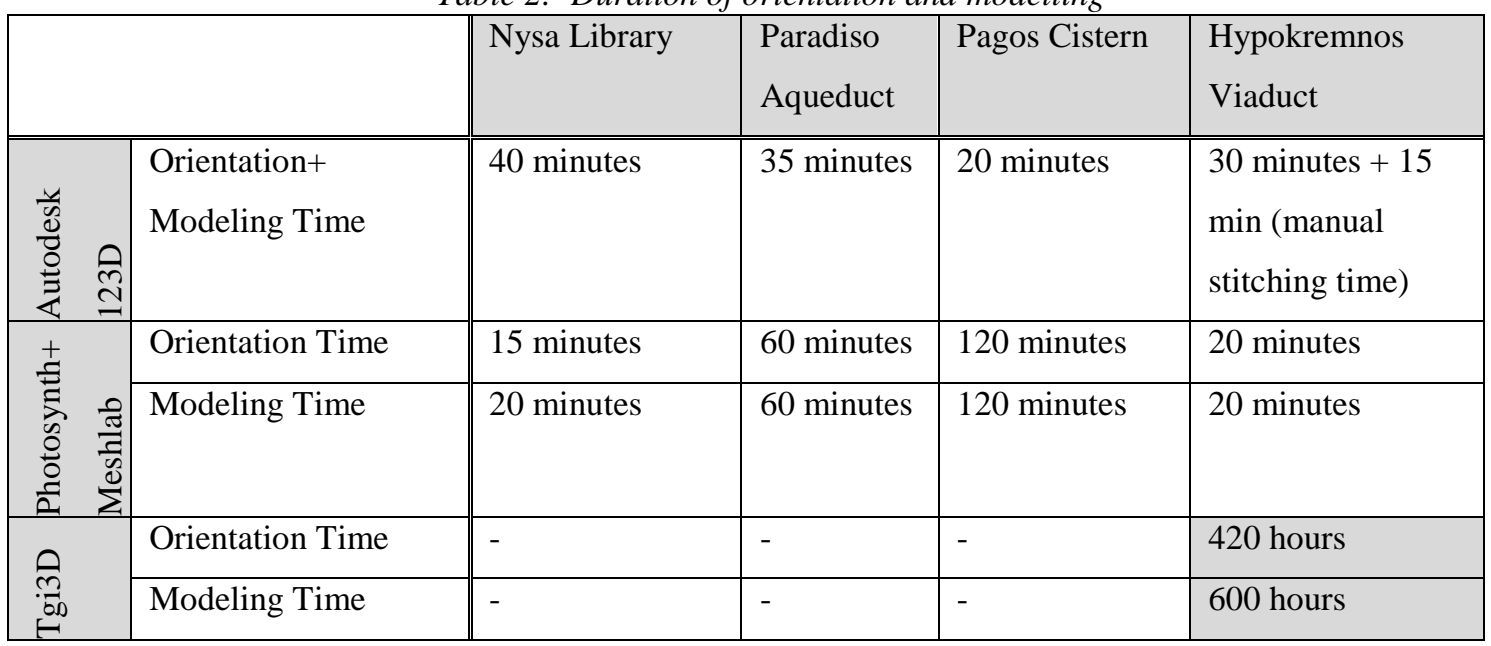

In the image orientation phase, each photograph was added one by one and oriented. In the first ten photos, orientation time was two seconds. Then orientation time increased in direct proportion to number of photos.

According to these data, if all orientations were carried out without any problems, image orientation takes approximately 170 hours. However, orientation of some photos was redone more than once due to the point errors recorded greater than 3.5 pixels. Therefore, orientation time lasted approximately 420 hours.

Surface construction phase is also time-consuming. Meshes created with textures in SketchUp 8 have some problematic parts as inclusion of sky, water and ground and drooping which should be edited. Solution of these problems extend the modeling phase twice. While problem of inclusion of sky, water and ground in the mesh solved by deleting these parts, drooping problem was solved by repairing these parts by push-pull tool. 
The reality-based model produced with manual software is sufficient for documentation of structural elements in detail. When further processed with the tools of the virtual reality modeling techniques, the results are appropriate for especially $1 / 20$ scaled system details and of course 1/50 scaled application drawings. They can be regarded as important sources for structural intervention decisions (Fig. 6).

Figure 6: Reality-based model of Hypokremnos Viaduct with Tgi3D
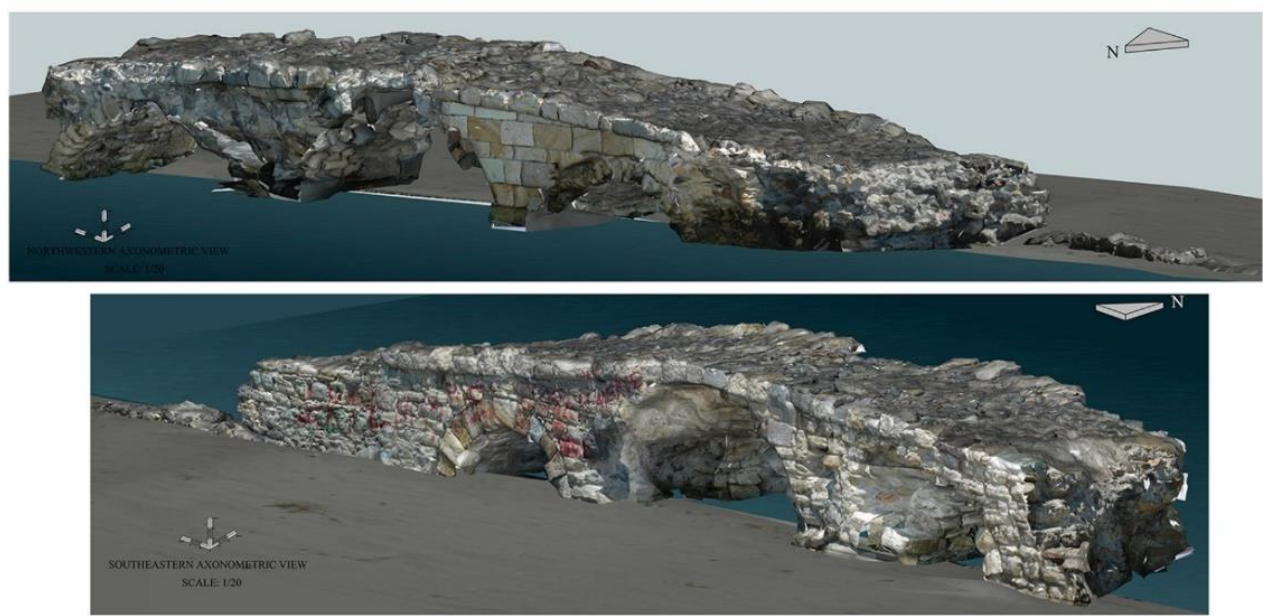

\section{Conclusion}

In this study, experience on some capabilities of the photogrammetric evaluation software; Photosynth-Meshlab, Autodesk 123 D and Tgi 3D; was presenteds and their suitability for various documentation reasons of built cultural heritage has been reasoned about. Photogrammetric evaluation software may support a condition survey for preventive maintenance and urgent repairs as in automatic workflows and planning of structural intervention decisions as in manual workflows. Their utilization also has digital archiving benefits and the end result 3D models are useful for risk preparedness.

The monuments used for experiments provided understanding of necessity of shots parallel to the surfaces and general views to produce satisfied 3D models. Very elongated and high geometries, positions and site restrictions such as shrubs, brook or sea can limit acquisition of parallel views to the surfaces, and this decreases the quality of the model by affecting its integrity and reliability. Therefore, site conditions and object characteristics are also crucial parameters for the quality of the image-based models.

\section{Acknowledgment}

We would like to thank Ogan Ocal1, who is the developer of Tgi3D, for his support about the usage of the software. 


\section{References}

[1] Adam, J. P. (2005). Roman Building, Materials, and Techniques, Translated by Anthony Mathews. London and Newyork: Routledge, pp. 76-85, 119-145, 174-176.

[2] Annibale, E. (2011). Image Based Modeling from Spherical Photogrammetry and Structure for Motion. The Case of the Treasury, Nabatean Architecture in Petra. Proceedings of the 23rd International Symposium of the International Scientific Committee for Documentation of Cultural Heritage CIPA 2011. Prague, Czech Republic. Available: http://cipa.icomos.org/fileadmin/template/doc/PRAGUE/038.pdf.

[3] Arias, P., Herra'ez, J., Lorenzo, H. and Ordonez, H. (2005). "Control of Structural Problems in Cultural Heritage Monuments Using Close-Range Photogrammetry and Computer Methods," Computers and Structures, vol. 83, pp. 1754-1766.

[4] Bakır, G. and Anlağan, G. (1980). "1979 Yılı Klazomeani Kazısı,” II. Kazı Sonuçları Toplantısl, pp. 90.

[5] Barazzetti, L., Scaioni, M. and Remondino, F. (2010). "Orientation and 3d Modelling from Markerless Terrestrial Images: Combining Accuracy with Automation," The Photogrammetric Record, vol. 25 (132), pp. 356-381.

[6] Böhler W. and Heinz G. (1999). Documentation, surveying, photogrammetry. XVII CIPA Symposium. Recife, Olinda, Brazil. 1999.

Available: https://i3mainz.hs-mainz.de/sites/default/files/public/data/cipa99.pdf

[7] El-Hakim, S.F., Beraldin, J.A., Picard, M. and Godin, G. (2004). "Detailed 3D Reconstruction of Large-Scale Heritage Sites with Integrated Techniques," IEEE Computer Graphics and Application, vol. 24(3), pp. 21-29.

[8] Ersoy, A. (2012). Smyrna (İzmir) History and Archaeology. International Earth Science Colloquium on the Aegean Region, IESCA-2012. İzmir. Turkey.

[9] Fellbaum, M., (1992). "Low-Cost Systems in Architectural Photogrammetry," International Archives of Photogrammetry and Remote Sensing. XXIX, Part B5. Washington DC, pp. 771-777.

[10] Grussenmeyer, P., Hanke, K., Streilein, A., (2002). Architectural photogrammetry. Digital Photogrammetry, ed. M. Kasser and Y. Egels, Abingdon, U.K.: Taylor \& Francis, pp. 300-339.

[11] Guidi, G., Remondino, F., Russo, M., Rizzi, A., Voltolini, F., Menna, F., Fassi, F., Ercoli, S., Masci, M. E. and Benedetti B. (2008). A Multi-Resolution Methodology for Archeological Survey: The Pompeii Forum. Proceeding of 14th International Conference on Virtual Systems and Multmedia. Limassol, Cyprus.

[12] Hiesel, G. and Strocka, V. (M. 2006). "Die Bibliothek von Nysa am Mäander," Vorläufiger Bericht über die Kampagnen 2002-2006, Originalbeitrag erschienen in: Archäologischer Anzeiger 2, Universitat Freiburg, Germany, pp. 81-97.

[13] Hodge Trevor, A. (2005). Roman Aqueducts \& Water Supply. $2^{\text {nd }}$ ed. London: Gerald Duckworth \& Co. Ltd, pp. 136.

[14] Remondino, F. and El-Hakim, S. (2006). "Image -based 3D Modeling: A Review," The Photogrannetric record, vol. 21 (115), pp. 269-291. 
[15] Remondino, F. (2011). "Heritage Recording and 3D Modeling with Photogrammetry and 3D Scanning," Remote Sensing, vol. 3, pp. 1104-1138.

[16] Rosnell, T. and Honkavaara E. (2012). "Point Cloud Generation from Aerial Image Data Acquired by a Quadrocopter Type Micro Unmanned Aerial Vehicle and a Digital Still Camera," Sensors, vol. 12, pp. 453-480.

[17] Salonia, P., Scolastico, S. Pozzi, A., Marcolongo, A. and Messina, T. L. (2009). "Multiscale cultural Heritage Survey: Quick Digital Photogrammetric Systems," Journal of Cultural Heritage, vol. 10S, pp. 59-64.

[18] Swallow, P., Dallas, R., Jackson, S. and Watt D. (2004). Measurement and Recording of Historic Buildings, $1^{\text {st }}$ ed. United Kingdom: Donhead Publishing, pp. 142-163.

[19] Toksöz, C. (1960). İzmir Tarih ve Arkeoloji. Ankara: Ayyıldız Matbaası, pp. 10-19.

[20] UNI EN 16096. (2012). Conservation of Cultural Property-Condition survey and report of built cultural heritage, U.K.: BSI.

[21] Weber, G. (1889). İzmir'in Su Yollarl, $1^{\text {st }}$. ed. İzmir: İzmir Büyükşsehir Belediyesi Kent Kitaplığ 1, pp. 41-50. 